$\mathrm{Bred}_{\mathrm{A}}=$
Revista Colombiana de Ciencia Animal ISSN: $2027-4297$

reciaeditor@unisucre.edu

Universidad de Sucre

Colombia

\title{
RECIA y su primer decenio. Una realidad que nos convoca
}

De La Ossa V., Jaime; Montes-Vergara, Donicer; Pérez-Cordero, Alexander

RECIA y su primer decenio. Una realidad que nos convoca

Revista Colombiana de Ciencia Animal, vol. 11, núm. 1, 2019

Universidad de Sucre, Colombia

DOI: https://doi.org/10.24188/recia.v11.n1.2019.689

Los autores permiten a RECIA reimprimir el material publicado en él. En caso de que un autor quiera traducir o usar una publicación parcial o completa de nuestro Diario, el autor debe obtener un permiso por escrito del editor de la revista.

Esta obra está bajo una Licencia Creative Commons Atribución 4.0 Internacional. 


\section{RECIA y su primer decenio. Una realidad que nos convoca}

RECIA and its first decade. A reality that brings us together

Jaime De La Ossa V.

DOI: https://doi.org/10.24188/recia.v11.n1.2019.689

Universidad de Sucre, Colombia

jaime.delaossa@unisucre.edu.co

(iD) http://orcid.org/0000-0002-9374-7765

Donicer Montes-Vergara

Universidad de Sucre, Colombia

donicer.montes@unisucre.edu.co

(iD http://orcid.org/0000-0002-2860-0505

Alexander Pérez-Cordero

Universidad de Sucre, Colombia

alexander.perez@unisucre.edu.co

(iD http://orcid.org/0000-0003-3989-1747

Hace diez años, con la alegría que producen las buenas intenciones, dábamos inicio a la vida pública de la Revista Colombiana de Ciencia Animal - RECIA, decíamos: < <Bienvenidos a este espacio de divulgación creado para los científicos, profesionales, técnicos, estudiantes, pensadores e interesados en la Ciencia Animal; bienvenidos todos independientemente de su nacionalidad, regionalidad, idioma o acento; extendemos una mano amplia, amiga y críticamente respetuosa en bien del crecimiento intelectual y de la sociedad en su conjunto. Seguir la huellas con el debido respeto, valorar la dignidad y sueños de quienes erigieron esta cultura, de quienes creyeron en ella y entregaron su vida o parte de ella para que hoy sea cierto lo que nos identifica como pueblo, es una meta que debemos orientar desde diferentes ángulos y la producción científica debe ser el eje principal desde donde proyectemos nuestros ideales de bienestar y desarrollo, desde el poblado, pasando por la nación para abrazar el mundo. La Revista Colombiana de Ciencia Animal de la Facultad de Ciencias Agropecuarias de la Universidad de Sucre nace como escenario intelectual nacional e internacional, que brinda cálida acogida a quienes con su intelecto ayudan a formar el mundo desde los sueños hasta la conclusión real $>>(1)$.

Hoy, después de una serie de conquistas, ganadas gracias a la constancia y al apoyo de numerosos investigadores y de muchos otros actores comprometidos, quienes con sus trabajos aportaron conocimientos y ayudaron a mantener viva la llama que alienta a RECIA, podemos decir que estamos preparados para continuar, porque este trabajo nunca finaliza, jamás prescribe y siempre requiere mejoría y mayor dedicación. Las expectativas que sobre la importancia que tiene la divulgación científica especializada son crecientes a nivel mundial, se espera que sea un faro que guie los avances de la humanidad y que más allá sea la fuente de la cual se beneficien los investigadores y el relevo generacional; que además sea el espacio real que permita el progreso y con ella se pueda beneficiar a toda la sociedad.

Es valioso traer a este escrito, lo que en su momento se dijo: $<<$ La sabiduría suprema es tener sueños bastante grandes para no perderlos de vista mientras se persiguen $>>$ (William Faulkner), y eso es lo que este esfuerzo nos muestra con claridad, se persiguió un sueño hasta volverlo realidad, se propició un proceso

\section{NotAS DE AUTOR}


continuo de crecimiento intelectual, se mantuvo viva la llama de la inquietud por la ciencia y sus enigmas, se formó e incentivó a investigadores, profesores y alumnos para que pudiera en conjunto darse lo que hoy es una de las metas conseguidas a base de perseverancia y credibilidad (1).

RECIA, amante de la discusión académica, acoge en su estructura el concepto de García Carmona y Acevedo-Díaz (2), al entender que las controversias científicas son esenciales en la construcción del conocimiento porque impulsan el avance de la ciencia y muestran el conflicto como algo natural a la propia ciencia. Por otro lado, coincidimos en que uno de los argumentos para apoyar la necesidad de comunicar la ciencia al público, es entender que todo miembro de una sociedad requiere conocer al menos los conceptos científicos básicos antes de poder formarse una opinión informada y responsable sobre los temas en los que la ciencia está involucrada, de los contario no podrá opinar ni actuar sobre ninguno de ellos como debería hacerlo (3).

\section{ReFERENCIAS}

1. De La Ossa VJ, Montes-Vergara D, Pérez-Cordero A, Patiño R. Una bienvenida a la investigación científica. Rev Col Cienc Animal 2009; 1(1):1-2. https://doi.org/10.24188/recia.v1.n1.2009.402.

2. García Carmona A, Acevedo-Díaz JA. Controversias en la historia de la ciencia y cultura científica. España: OEI Catarata; 2017.

3. Bonfil Olivera M. Cooperación Ib: La importancia de la divulgación científica. No es un entretenimiento. Publicado en Humanidades, periódico de la Dirección de Humanidades de la UNAM. (Citado 20 dic 2018). URL disponible en: https://www.cooperacionib.org/di.php

Los autores permiten a RECIA reimprimir el material publicado en él. En caso de que un autor quiera traducir o usar una publicación parcial o completa de nuestro Diario, el autor debe obtener un permiso por escrito del editor de la revista.

CC BY 